\title{
Relationship between glycemic control and histochemical myeloperoxidase activity in neutrophils in patients with type 2 diabetes
}

\author{
Mustafa Unubol I*, Irfan Yavasoglu², Firuzan Kacar ${ }^{3}$, Engin Guney ${ }^{1}$, Imran Kurt Omurlư ${ }^{4}$, Mevlut Ture ${ }^{4}$, \\ Gurhan Kadikoylu² and Zahit Bolaman²
}

\begin{abstract}
Background: Myeloperoxidase (MPO) is a lysosomal hemoprotein found in the azurophilic granules in neutrophils. Myeloperoxidase plays an important role in oxygen-dependent killing of bacteria, fungi, virus and malignant cells. Diabetes mellitus (DM) is listed among conditions that may lead to secondary MPO deficiency in neutrophils but inconsistent results concerning MPO activity in diabetic patients have been reported in the literature. In this study, we aimed to evaluate the relationship between glycemic control in patients with type 2 DM and MPO activity in neutrophils from a histochemical perspective.

Methods: The study included 40 patients with type 2 DM with poor glycemic control, 30 patients with type 2 DM with good glycemic control and 31 healthy controls. Peripheral blood smears were analyzed for each patient included in the study. Myeloperoxidase dye was used for staining. Myeloperoxidase ratios in neutrophil were evaluated for proportions of staining with MPO in 100 neutrophils in each smear. SPSS 16.0 version was used for statistical analyses.

Results: Myeloperoxidase ratios in neutrophils were 70 (58.5-80) in type 2 DM patients with poor glycemic control compared to 80 (73.75-90) in those with good glycemic control and 88 (78-92) in healthy controls. The DM group with poor glycemic control was statistically significantly different from the other groups $(p<0.001)$.

Conclusions: Poor glycemic control in diabetic patients results in decreased MPO activity in neutrophils histochemically.
\end{abstract}

Keywords: Diabetes mellitus, Myeloperoxidase activity, Glycemic control, Diabetic complications

\section{Background}

Several microbicidal dysfunctions of the neutrophils and monocytes have been defined as a factor that contributes to complications and to morbidity and mortality in diabetic patients $[1,2]$. Deficiencies in a number of functions have been demonstrated in the neutrophils of diabetic patients [3-5]. Oxidative stress and reactive oxygen species are known to have important roles in the etiology of diabetes, in development of its complications and in disease progression [6]. Myeloperoxidase (MPO) is a

\footnotetext{
*Correspondence: drmunubol@yahoo.com.tr

${ }^{1}$ Department of Endocrinology, Faculty of Medicine, Adnan Menderes

University, 09100 Aydın, Turkey

Full list of author information is available at the end of the article
}

lysosomal hemoprotein found in the azurophilic granules in neutrophils [7]. It is a potent bactericidal enzyme that produces reactive oxygen species. Myeloperoxidase plays an important role in oxygen-dependent killing of bacteria, fungi, virus and malignant cells. Myeloperoxidase-mediated damage is not limited to intraphagosomal microbes. It is involved in the pathogenesis of several inflammatory conditions, atherosclerosis, demyelinating diseases of the central nervous system and some tumors [8-10].

Diabetes mellitus (DM) is listed among conditions that may lead to secondary MPO deficiency in neutrophils [9] but inconsistent results concerning MPO activity in diabetic patients have been reported in the literature [1113]. Our literature scan demonstrated that the effect of 
glycemic control in diabetic patients on MPO activity in neutrophils has not been investigated from a histochemical perspective previously.

In this study, we aimed to evaluate the relationship between glycemic control in patients with type $2 \mathrm{DM}$ and MPO activity in neutrophils from a histochemical perspective.

\section{Methods}

\section{Study design and protocol}

This study was designed as an observational, cross-sectional and case-controlled study. Patients with type 2 DM who presented to outpatient clinics of the Adnan Menderes University, Medical Faculty, Department of Endocrinology and Metabolic Disease between January and March 2012 were studied. The patients with type $2 \mathrm{DM}$ applying to the follow-up clinic, and lacking the exclusion criteria, agreeing to participate in the study were enrolled consecutively from January 2012. The study included 40 patients with type $2 \mathrm{DM}$ with poor glycemic control (HbA1c > 7), 30 patients with type $2 \mathrm{DM}$ with good glycemic control $(\mathrm{HbA1c} \leq 7)$ [14] and 31 healthy controls. Patients with active infection, known malignancy, hematologic malignancy, iron deficiency, thrombotic conditions, renal transplantation, patients currently treated with cytotoxic agents, fenofibrate, and anti-inflammatory drugs, and pregnant women were excluded from the study.

Three peripheral blood smears (in fasting period) were analyzed for each patient included in the study. Myeloperoxidase dye was used for staining. Myeloperoxidase ratios in neutrophils (Fig. 1) were evaluated by one hematologist and one hematopathologist for

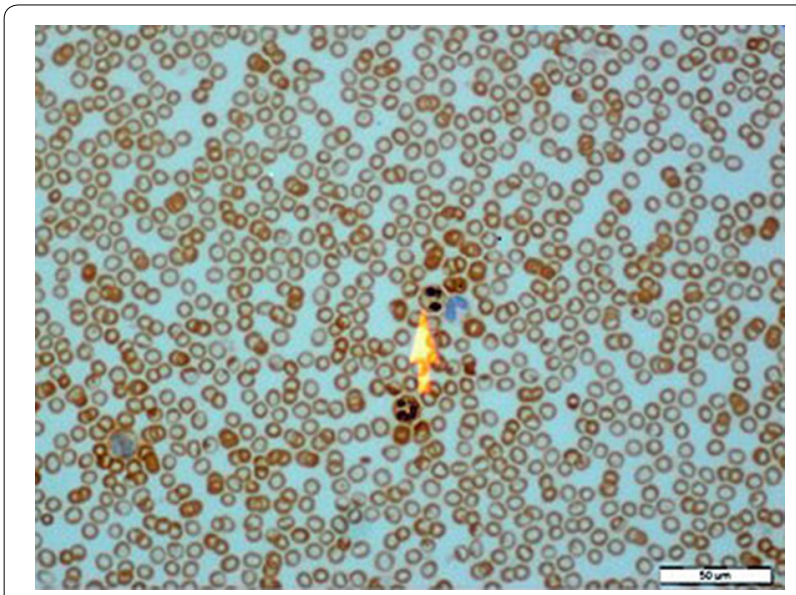

Fig. 1 Microscopic image of the neutrophil with positive MPO staining in peripheral blood proportions of staining with MPO in 100 neutrophils in each smear, and the mean value of the readings were reported [15].

\section{Statistical analysis}

SPSS 16.0 version was used for statistical analyses. Fit of the quantitative data to normal distribution was studied using the Shapiro-Wilk test. For variables that were fit for normal distribution, one-way variance analysis (ANOVA) was used for statistical comparisons and descriptive statistics were expressed as mean \pm standard deviation. For variables unfit for normal distribution, Kruskal-Wallis was used for statistical comparisons and descriptive statistics were expressed as median (25-75 \%o). The level of relationship between variables was studied with Spearman's Rho correlation coefficient. Chi square test and Fisher test were used in analyzing categorical variables and descriptive statistics were expressed as frequency (\%). In our study, we used classification and regression tree $(C \& R T)$ method in order to choose the best predictor for MPO. $\mathrm{p}$ values $<0.05$ were considered statistically significant.

Approval of the ethics board of the Medical Faculty of Adnan Menderes University was received.

\section{Results}

Type 2 DM patients with poor glycemic control had a mean age of $56.4 \pm 9.99$ years and type $2 \mathrm{DM}$ patients with good glycemic control had a mean age of $57.3 \pm 10.02$ years and healthy controls had a mean age of $51.42 \pm 11.48$ years, with no significant difference among the groups ( $p>0.05)$. Type $2 \mathrm{DM}$ patients with poor glycemic control had a disease duration of $12.3 \pm 3.4$ years and were not significantly different from type $2 \mathrm{DM}$ patients with good glycemic control ( $p>0.05)$. Myeloperoxidase ratio in neutrophils was $70(58.5-80)$ in type $2 \mathrm{DM}$ patients with poor glycemic control compared to 80 (73.75-90) in those with good glycemic control and 88 (78-92) in healthy controls. The DM group with poor glycemic control was statistically significantly different from the other groups $(\mathrm{p}<0.001)$. Good and poor controlled diabetes groups were similar in terms of the drugs being used. No correlation was found between the MPO activity and the drugs used to treat diabetes $(\mathrm{p}>0.05)$. In patient groups with diabetes, statistically significant differences in terms of MPO activity was not detected among the patients using and not using sitagliptin, insulin detemir, insulin glargine, insulin aspart, insulin lispro, insulin glulisine, metformin, gliclazide, repaglinide, nateglinide, pioglitazone. Statistical results of quantitative and qualitative data are provided in Tables 1, 2, 3 and 4; Figs. 2 and 3 demonstrates correlation analysis between MPO and HbA1c. 
Table 1 Comparison of laboratory findings between the three groups

\begin{tabular}{|c|c|c|c|c|}
\hline & DM with poor glycemic control & DM with good glycemic control & Controls & $p$ \\
\hline MPO (\%) & $70(58.5-80)^{\mathrm{a}}$ & $80(73.75-90)$ & $88(78-92)$ & $<0.001^{b}$ \\
\hline $\mathrm{Hb}(\mathrm{g} / \mathrm{dL})$ & $13.34 \pm 1.63$ & $13.52 \pm 1.30$ & $12.7 \pm 1.47$ & $>0.05^{c}$ \\
\hline Leukocyte $\left(/ \mathrm{mm}^{3}\right)$ & $7961 \pm 1624.48$ & $7963.67 \pm 1624.30$ & $6608.71 \pm 1411.78^{d}$ & $0.001^{c}$ \\
\hline Platelet $\left(/ \mathrm{mm}^{3}\right)$ & $287375 \pm 81599$ & $280567 \pm 72463$ & $275968 \pm 72470$ & $>0.05^{c}$ \\
\hline HBA1C (\%) & $10.15(8.8-13.85)$ & $6.5(5.98-6.8)^{e}$ & $5.4(5-5.5)$ & $<0.001^{b}$ \\
\hline $\mathrm{LDL}(\mathrm{mg} / \mathrm{dL})$ & $124.48 \pm 42.32$ & $113.63 \pm 27.40$ & $127.39 \pm 31.67$ & $>0.05^{c}$ \\
\hline $\mathrm{HDL}(\mathrm{mg} / \mathrm{dL})$ & $39.85 \pm 11.98^{f}$ & $46.73 \pm 11.91$ & $46.29 \pm 10.19$ & $0.019^{c}$ \\
\hline Triglyceride (mg/dL) & $138.5(110.75-192.75)$ & $137.5(103.5-209.25)$ & $120(87-190)$ & $>0.05^{b}$ \\
\hline Creatinine $(\mathrm{mg} / \mathrm{dL})$ & $0.77(0.72-0.93)^{\mathrm{a}}$ & $0.72(0.65-0.8)$ & $0.73(0.68-0.8)$ & $0.021^{b}$ \\
\hline Fasting plasma glucose (mg/dL) & $203.5(156-304.5)$ & $122(97.75-128.25)^{\mathrm{e}}$ & $90(85-93)$ & $<0.001^{b}$ \\
\hline Postprandial plasma glucose (mg/dL) & $298(225-397.75)$ & $147.5(125.5-167.75)^{\mathrm{e}}$ & $104(95-120)$ & $<0.001^{b}$ \\
\hline Sedimentation $(\mathrm{mm} / \mathrm{h})$ & $42.13 \pm 22.27^{9}$ & $36.77 \pm 18.31$ & $26.48 \pm 16.45$ & $0.005^{c}$ \\
\hline C-reactive protein ( $\mathrm{g} / \mathrm{dl})$ & $3.41(2.09-7.36)^{\mathrm{a}}$ & $1.35(0.7-3.85)$ & $1.38(0.94-3.63)$ & $0.001^{b}$ \\
\hline Age & $56.4 \pm 9.99$ & $57.3 \pm 10.02$ & $51.42 \pm 11.48$ & $>0.05^{c}$ \\
\hline $\mathrm{BMI}\left(\mathrm{kg} / \mathrm{m}^{2}\right)$ & $29.45(26.60-35.65)$ & $27.88(24.5-32.43)$ & $25(23.6-27.8)^{d}$ & $0.001^{\mathrm{b}}$ \\
\hline MPV (fL) & $9.4(8.5-10.2)$ & $8.4(7.58-9.63)$ & $8.9(8.5-9.7)$ & $>0.05^{b}$ \\
\hline Hematocrite & $39.35(37.25-42.18)$ & $40.6(38.58-43.03)$ & $36.7(35.6-41.5)^{\mathrm{h}}$ & $0.036^{\mathrm{b}}$ \\
\hline 24-h urine microalbuminuria (mg/day) & $38(16.25-88.25)$ & $17(12-29.25)^{\mathrm{e}}$ & $12(8-15)$ & $<0.001^{b}$ \\
\hline
\end{tabular}

${ }^{a}$ DM group with poor control is different from other groups

${ }^{b}$ It was used the Kruskal-Wallis test for statistical analysis

c It was used the ANOVA test for statistical analysis

${ }^{d}$ Control group is different from other groups

e All groups are different from each other

${ }^{f}$ DM group with poor control and DM group with good control are different from each other

${ }^{9}$ DM group with poor control and control group are different from each other

${ }^{\mathrm{h}}$ Control group and DM group with good control are different from each other

We apllied the C\&RT model in order to choose the best predictor for MPO development. In the model, patients were first divided into two branches according to their type $2 \mathrm{DM}$ values (patients with poor glycemic control and good glycemic control and healthy controls) for the prediction of MPO. According to this model, type $2 \mathrm{DM}$ patients with poor glycemic control had lower MPO activity in neutrophils $(66.6 \pm 21.6$ versus $81.9 \pm 14.0)$. MPO impact on the diagnosis of Type 2 DM was $100 \%$ and the effects of drugs used to treat DM and HT was $63 \%$.

\section{Discussion}

We determined histochemically that type 2 DM patients with poor glycemic control had lower MPO activity in neutrophils compared to both healthy controls and type 2 DM patients with good glycemic control. Type 2 DM patients with good glycemic control and healthy controls did not differ significantly with respect to MPO activity in neutrophils.

Myeloperoxidase deficiency in neutrophils can be acquired or hereditary. Acquired MPO deficiency is rarer [10]. Hematologic malignancies, common cancers, cytotoxic agents, some antiinflammatory drugs, iron deficiency, lead intoxication, thrombotic conditions, renal transplantation, serious infections, neuronal lipofuscinosis, pregnancy and DM have been shown among the causes of acquired MPO deficiency [8, 10]. Nita et al. showed that fenofibrate reduced plasma MPO concentrations [16]. A study that compared MPO ratios in peripheral neutrophils in diabetic patients identified no significant difference in MPO ratios of diabetic patients with and without infection [11]. In the study by Sato et al. [12], decreased MPO activity was shown in leukocytes of diabetic patients. Likewise, a study by Uchimura et al. [17] demonstrated markedly decreased MPO activity in leukocytes of patients with non-insulin dependent diabetes. On the other hand, Gorudko et al. [13] found increased MPO activity in plasma of type 2 DM patients with no cardiovascular disease. In the study by Moldoveanu et al. [18], patients with DM also had a higher MPO activity compared to the control group. In another study, serum MPO levels were found to be higher in overweight individuals who had first-degree relatives with type 2 DM compared to the control group [19]. An animal study demonstrated that MPO expression was higher in 
Table 2 Comparison of neuropathy presence and laboratory data in patients with type 2 DM

\begin{tabular}{|c|c|c|c|c|}
\hline & $\begin{array}{l}\text { With neuropathy } \\
(\mathrm{n}=27)\end{array}$ & $\begin{array}{l}\text { Without neuropathy } \\
(\mathrm{n}=43)\end{array}$ & $\begin{array}{l}\text { Controls } \\
(n=31)\end{array}$ & $p$ \\
\hline MPO (\%) & $75(50-86)^{a}$ & $80(70-90)$ & $87(79.5-90.5)$ & $0.011^{b}$ \\
\hline HBA1C (\%) & $9(6.9-12.3)^{c}$ & $6.75(5.6-9.75)$ & $5.4(5.08-5.5)$ & $<0.001^{b}$ \\
\hline Sedimentation $(\mathrm{mm} / \mathrm{h})$ & $43.96 \pm 21.89^{d}$ & $32.87 \pm 20.16$ & $31.05 \pm 16.27$ & $0.036^{e}$ \\
\hline C-reactive protein (g/dl) & $4.1(2.39-8.87)^{d}$ & $1.95(0.83-3.88)$ & $1.37(0.93-4.45)$ & $0.002^{b}$ \\
\hline
\end{tabular}

a The group with neuropathy and the control group are different from each other

b It was used the Kruskal-Wallis test for statistical analysis

c All groups are different from each other

${ }^{d}$ The group with neuropathy is different from other groups

e It was used the ANOVA test for statistical analysis

Table 3 Comparison of nephropathy development and laboratory data in patients with type 2 DM

\begin{tabular}{lllll}
\hline & $\begin{array}{l}\text { With nephropathy } \\
(\mathbf{n = 2 9 )}\end{array}$ & $\begin{array}{l}\text { Without nephropathy } \\
(\mathbf{n = 4 1 )}\end{array}$ & $\begin{array}{l}\text { Controls } \\
(\mathbf{n}=\mathbf{3 1})\end{array}$ \\
\hline MPO (\%) & $80(70-85)$ & $75(54-88)$ & $88(78-92)^{\mathrm{a}}$ & $\mathbf{p}$ \\
HBA1C (\%) & $9(7.1-12)$ & $6.9(6.15-10.8)$ & $5.4(5-5.5)^{\mathrm{a}}$ & $0.003^{\mathrm{b}}$ \\
Sedimentation $(\mathrm{mm} / \mathrm{h})$ & $38 \pm 21.25$ & $40.39 \pm 20.63$ & $26.48 \pm 16.45^{\mathrm{c}}$ & $<0.001^{\mathrm{b}}$ \\
C-reactive protein $(\mathrm{g} / \mathrm{dl})$ & $3.44(1.5-7.93)$ & $2.41(0.99-4.1)$ & $1.38(0.94-3.63)^{\mathrm{e}}$ & $0.011^{\mathrm{d}}$ \\
\hline
\end{tabular}

a Control group is different from other groups

b It was used the Kruskal-Wallis test for statistical analysis

c Control group and the group without nephropathy are different from each other

${ }^{d}$ It was used the ANOVA test for statistical analysis

e Control group and the group with nephropathy are different from each other

Table 4 Comparison of complications presence in patients with type 2 DM

\begin{tabular}{|c|c|c|c|c|c|}
\hline & & Controls n (\%) & DM with poor control n (\%) & DM with good control n (\%) & Exact $p$ \\
\hline \multirow[t]{2}{*}{ Sex } & Male & $8(25.8)$ & $21(52.5)$ & $11(36.7)$ & $>0.05^{\mathrm{a}}$ \\
\hline & Female & $23(74.2)$ & $19(47.5)$ & $19(63.3)$ & \\
\hline \multirow[t]{2}{*}{ Neuropathy } & No & & $20(50)$ & $23(76.7)$ & $<0.001^{\mathrm{a}}$ \\
\hline & Yes & & $20(50)$ & $7(23.3)$ & \\
\hline \multirow[t]{2}{*}{ CAD } & No & & $32(80)$ & $28(93.3)$ & $<0.001^{\mathrm{a}}$ \\
\hline & Yes & & $8(20)$ & $2(6.7)$ & \\
\hline \multirow[t]{2}{*}{ Retinopathy } & No & & $31(77.5)$ & $28(93.3)$ & $<0.001^{\mathrm{a}}$ \\
\hline & Yes & & $9(22.5)$ & $2(6.7)$ & \\
\hline \multirow[t]{2}{*}{$\mathrm{PAH}$} & No & & $38(95)$ & $29(96.7)$ & $<0.001^{\mathrm{a}}$ \\
\hline & Yes & & $2(5)$ & $1(3.3)$ & \\
\hline \multirow[t]{2}{*}{ Diabetic foot } & No & & $38(95)$ & $30(100)$ & $>0.05^{\mathrm{a}}$ \\
\hline & Yes & & $2(5)$ & $0(0)$ & \\
\hline
\end{tabular}

Fisher test were used in analyzing categorical variables and descriptive statistics were expressed as frequency (\%)

a It was used the Chi square test for statistical analysis

diabetic neutrophils but reported decreased MPO activity in neutrophils compared to the control group [20].

The relationship between type 2 diabetes mellitus and MPO has been investigated by previous studies, which arrived at contradicting conclusions [13, 17-19]. There are a limited number of studies investigating the relationship between glycemic response and MPO. The study by Sato et al. evaluating the effect of glycemic response on MPO demonstrated a significant correlation between decreased MPO activity in leukocytes and increased 


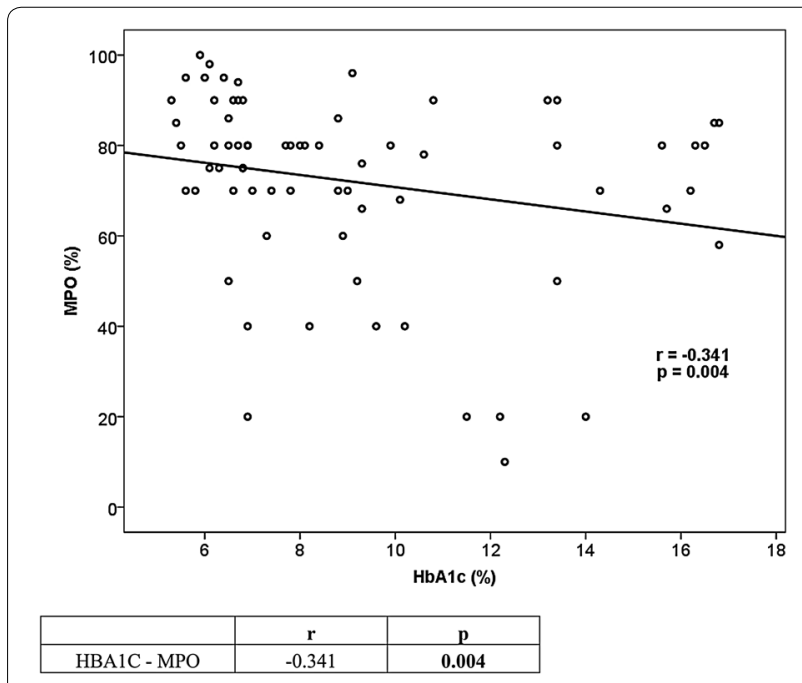

Fig. 2 Correlation between $\mathrm{HbA} 1 \mathrm{c}$ and MPO in patients with DM

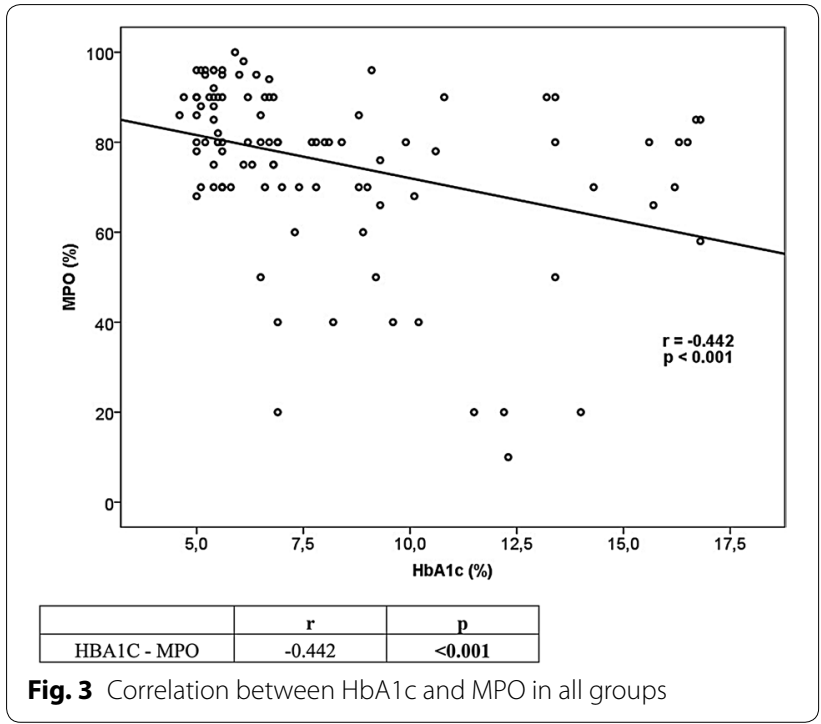

HbA1c [12]. In our study, we also found a negative correlation between $\mathrm{Hba1C}$ values and MPO levels.

Previous studies investigating the relationship between DM and MPO used the ELISA method [12, 13, 17-20]. With the literature scan, our study appears as the first to evaluate MPO activity in neutrophils in diabetic patients from a histochemical perspective. Histochemical evaluation of MPO activities is cheaper and easier than serological methods.

Chronic hyperglycemia increases the release of reactive oxygen species from neutrophils [21]. Neutrophil dysfunctions were shown as one of the causes of glycemic unresponsiveness in diabetic patients. Abnormalities in granulocyte chemotaxis, phagocytosis and microbicidal activities were described for patients with poorlycontrolled diabetes [22]. Impaired neutrophil bactericidal function was strongly associated with poor glycemic control and improved positively with good glycemic control [23]. The chronic hyperglycemia of poorly controlled diabetes can prime neutrophils and monocytes [24].

A positive correlation between HbA1c and white blood cell levels (WBC) in patients with type 2 DM was reported in a study [25]. Patients with type $2 \mathrm{DM}$ are in a state of low-degree chronic inflammation that induces hypersecretion of inflammatory factors, which results in a constantly elevated neutrophilic granulocyte count [26]. In our study, WBC levels of DM groups with poor glycemic control and good glycemic control were statistically significantly elevated from the control group $(p<0.001)$.

In a study, superoxide dismutase activity in the neutrophils of type 2 diabetes patients was decreased by $41 \%$ compared to the control group. Glutathione peroxidase (GSHPx) and glutathione reductase (GR) activities of type 2 diabetic patients were 73.04 and $81.12 \%$, respectively, compared to controls. No differences were noted in catalase activities. It has been suggested that these findings could account for some of the mechanisms that lead to increased sensitivity of type 2 DM patients to certain infections [27].

Increased glucose levels lead to increased protein glycation through early glycation products and advanced glycation late products (AGE) in diabetic patients. This plays an important role in occurrence of complications [28]. In addition, AGE is one of the most important causes by which hyperglycemia causes cellular and tissue damage. Some AGEs occur on critical protein sites and may lead to enzymatic inactivation and loss of physiological function [29]. Thus, decreased MPO activity in patients with poorly controlled diabetes may be due to hyperglycemiaassociated negative modulation of the enzymatic activity [20].

This hypothesis was described for other enzymes previously. It suggests that the presence of high plasma glucose concentration might cause alterations in the molecular conformation of the enzyme or its catalytic site, possibly by glycation of amino acids [30].

There are varying opinions and results in the literature regarding the conditions that low MPO activity in neutrophils could lead to [31, 32]. Is MPO a friend or foe? [31]. It has been suggested that chronic inflammatory process and serious infections may be more frequent in patients with total or subtotal MPO deficiency [32]. Different publications have reported that serious infections as sporadic cases developed in less than $5 \%$ of the individuals with MPO deficiency [8]. While it has been suggested that there might be a relationship between MPO 
deficiency and cancer risk [8], a different publication has reported no increase in the incidence of cancer in individuals with MPO deficiency [31]. It has been suggested that MPO deficiency has cardioprotective effects [32].

Because this was a cross-sectional study, information on patients' infections and malignancies were derived from patient reports. The relationship between MPO deficiency and infections or malignancies could not be evaluated as conclusive data could not be obtained. We believe that evaluation by prospective studies on the clinical conditions that could be caused by MPO deficiency we observed in patients with poor glycemic control would be helpful.

There are several studies evaluating the relationship between MPO deficiency and atherosclerosis [33, 34]. In our study, a statistically significant difference was not noted in the MPO ratio between DM patients with and without neuropathy ( $p>0.05)$. Also, no significant difference was observed between DM patients with and without nephropathy with respect to MPO levels ( $p>0.05$ ). In our study, a statistical evaluation could not be performed since the number of patients with coronary artery disease and diabetic rethinopathy in each group were insufficient. This was interpreted as a finding that differs from the findings of studies which demonstrated protective effects of deficient levels of MPO in neutrophils from atherosclerosis $[33,34]$. The role of oxidative stress in development of diabetic microvascular complications is known [35] but poor glycemic control is the primary cause in development of the microvascular complications [36]. The study by Zhang demonstrated that MPO was not necessary to induce an experimental atherosclerosis model in MPO-deficiency-induced mice [37]. Our study indicates that microvascular complications in diabetic patients cannot be associated alone with MPO activity. Our study did not yield any finding which suggests that decreased MPO activity in neutrophils in diabetic patients prevented microvascular complications.

In conclusion, poor glycemic control in diabetic patients results in decreased MPO activity in neutrophils histochemically. We believe that variability in MPO activity by glycemic response in diabetic patients, complications and their clinical relevance need to be assessed in prospective studies.

\footnotetext{
Authors' contributions

MU and IY conceptualized the idea for the study, collected the data, performed a literature review, and wrote the manuscript. MU, IY, EG and FK participated in the design of the study, participated in the discussion, and were involved in drafting the manuscript. GK, IKO and MT were involved in performing the statistical analysis. GK, FK, EG and ZB participated in the discussion. All authors have read and approved the final manuscript.
}

\section{Author details}

${ }^{1}$ Department of Endocrinology, Faculty of Medicine, Adnan Menderes University, 09100 Aydın, Turkey. ${ }^{2}$ Department of Hematology, Faculty of Medicine,
Adnan Menderes University, Aydın, Turkey. ${ }^{3}$ Department of Pathology, Faculty of Medicine, Adnan Menderes University, Aydın, Turkey. ${ }^{4}$ Department of Biostatistics, Faculty of Medicine, Adnan Menderes University, Aydın, Turkey.

\section{Competing interests}

The authors declare that they have no competing interests.

\section{Experimental power}

In a one-way ANOVA study, sample sizes of 30, 30, and 30 are obtained from the three groups whose means are to be compared. The total sample of 90 subjects achieves $98 \%$ power to detect differences among the means versus the alternative of equal means using an $\mathrm{F}$ test with a 0.05 significance level.

\section{Funding}

This research did not receive any specific grant from any funding agency in the public, commercial or not-for-profit sector.

Received: 1 September 2015 Accepted: 19 December 2015

Published online: 30 December 2015

\section{References}

1. Hatanaka E, Monteagudo PT, Marrocos MS, Campa A. Neutrophils and monocytes as potentially important sources of proinflammatory cytokines in diabetes. Clin Exp Immunol. 2006;146:443-7.

2. Herrera BS, Hasturk H, Kantarci A, Freire MO, Nguyen O, Kansal S, et al. Impact of resolvin E1 on murine neutrophil phagocytosis in type 2 diabetes. Infect Immun. 2015;83:792-801.

3. de Vries MA, Alipour A, Klop B, van de Geijn GJ, Janssen HW, Njo TL, et al. Glucose-dependent leukocyte activation in patients with type 2 diabetes mellitus, familial combined hyperlipidemia and healthy controls. Metabolism. 2015;64:213-7.

4. Krol E, Agueel R, Banue S, Smogorzewski M, Kumar D, Massry SG. Amlodipine reverses the elevation in [Ca2 +]i and the impairment of phagocytosis in PMNLs of NIDDM patients. Kidney Int. 2003;64:2188-95.

5. Sefil F, Ulutas KT, Dokuyucu R, Sumbul AT, Yengil E, Yagiz AE, et al. Investigation of neutrophil lymphocyte ratio and blood glucose regulation in patients with type 2 diabetes mellitus. J Int Med Res. 2014;42:581-8.

6. Brownlee M. The pathobiology of diabetic complications: a unifying mechanism. Diabetes. 2005;54:1615-25.

7. NauseefWM. Diagnostic assays for myeloperoxidase and myeloperoxidase deficiency. Methods Mol Biol. 2014;1124:537-46.

8. Lanza F. Clinical manifestation of myeloperoxidase deficiency-Review. J Mol Med (Berl). 1998;76:676-81.

9. Marchetti C, Patriarca P, Solero GP, Baralle FE, Romano M. Genetic characterization of myeloperoxidase deficiency in Italy. Hum Mutat. 2004;23:496-505.

10. Dinauer MC, Newburger PE. The phagocyte system and disorders of granulopoiesis and granulocyte function. In: Orkin SH, Nathan DG, Ginsburg D, Look AT, Fisher DE, Lux SE, editors. Nathan and Oski's Hematology of Infancy and Childhood. Philadelphia: Saunders-Elsevier; 2009. p. 1109-221.

11. Abdi Liaie Z, Soudbakhsh A, Atarod L, Toogeh GH, Nakhjavani M, Mousavipanah P, et al. Myeloperoxidase deficiency in neutrophils of diabetic patients with and without infectious disease. Tehran Univ Med J. 2008;65(12):31-5.

12. Sato N, Shimizu H, Suwa K, Shimomura Y, Kobayashi I, Mori M. MPO activity and generation of active $\mathrm{O}_{2}$ species in leukocytes from poorly controlled diabetic patients. Diabetes Care. 1992;15:1050-2.

13. Gorudko IV, Kostevich AV, Sokolov AV, Konstatinova EÉ, Tsapaeva NL, Mironova $\mathrm{EV}$, et al. Increased myelopepoxidase activity is a risk factor for ishemic heart disease in patients with diabetes mellitus. Biomed Khim. 2012;58:475-84

14. American Diabetes Association. Executive summary: standards of medical care in diabetes-2014. Diabetes Care. 2014;37(Suppl 1):S5-13.

15. Kitahara M, Simonian Y, Eyre HJ. Neutrophil myeloperoxidase: a simple, reproducible technique to determine activity. J Lab Clin Med. 1979;93:232-7.

16. Nita C, Bala C, Porojan M, Hancu N. Fenofibrate improves endothelial function and plasma myeloperoxidase in patients with type 2 diabetes 
mellitus: an open-label interventional study. Diabetol Metab Syndr. 2014;6:30.

17. Uchimura K, Nagasaka A, Hayashi R, Makino M, Nagata M, Kakizawa H, et al. Changes in superoxide dismutase activities and concentrations and myeloperoxidase activities in leukocytes from patients with diabetes mellitus. J Diabetes Complications. 1999;13:264-70.

18. Moldoveanu E, Tanaseanu C, Tanaseanu S, Kosaka T, Manea G, Marta DS, et al. Plasma markers of endothelial dysfunction in type 2 diabetics. Eur $J$ Intern Med. 2006;17:38-42.

19. Gómez-García A, Rodríguez MR, Gómez-Alonso C, Ochoa DYR, AlvarezAguilar C. Myeloperoxidase is associated with insulin resistance and inflammation in overweight subjects with first-degree relatives with type 2 diabetes mellitus. Diabetes Metab J. 2015;39:59-65.

20. de Souza Ferreira C, Araújo TH, Ângelo ML, Pennacchi PC, Okada SS, de Araújo Paula FB, et al. Neutrophil dysfunction induced by hyperglycemia: modulation of myeloperoxidase activity. Cell Biochem Funct. 2012:30:604-10.

21. Saito Y, Takahashi I, Iwane K, Okubo N, Nishimura M, Matsuzaka M, et al. The influence of blood glucose on neutrophil function in individuals without diabetes. Luminescence. 2013;28:569-73.

22. Alba-Loureiro TC, Munhoz CD, Martins JO, Cerchiaro GA, Scavone C, Curi $\mathrm{R}$, et al. Neutrophil function and metabolism in individuals with diabetes mellitus (Review). Braz J Med Biol Res. 2007;40:1037-44.

23. Gallacher SJ, Thomson G, Fraser WD, Fisher BM, Gemmell CG, MacCuish AC. Neutrophil bactericidal function in diabetes mellitus: evidence for association with blood glucose control. Diabet Med. 1995;12:916-20.

24. Ayilavarapu S, Kantarci A, Fredman G, Turkoglu O, Omori K, Liu H, Iwata T, Yagi M, Hasturk H, Van Dyke TE. Diabetes-induced oxidative stress is mediated by $\mathrm{Ca}^{2+}$ independent phospholipase A2 in neutrophils. J Immunol. 2010;184:1507-15.

25. Tong PC, Lee KF, So WY, et al. White blood cell count is associated with macro and microvascular complications in Chinese patients with type 2 diabetes. Diabetes Care. 2004;27:216-22.

26. Lou M, Luo P, Tang R, Peng Y, Yu S, Huang W, He L. Relationship between neutrophil-lymphocyte ratio and insulin resistance in newly diagnosed type 2 diabetes mellitus patients. BMC Endocr Disord. 2015;2(15):9. doi:10.1186/s12902-015-0002-9.
27. Muchova J, Liptakova A, Orszaghova Z, Garaiova I, Tison P, Carsky J, Durackova Z. Antioxidant systems in polymorphonuclear leucocytes of type 2 diabetes mellitus. Diabet Med. 1999;16:74-8.

28. Goh SY, Cooper ME. Clinical review: the role of advanced glycation end products in progression and complications of diabetes. J Clin Endocrinol Metab. 2008;93:1143-52.

29. Brownlee M. Biochemistry and molecular cell biology of diabetic complications. Nature. 2001;414:813-20.

30. Ikeda K, Higashi T, Sano H, Jinnouchi Y, Yoshida M, Araki T, et al. N-E-(carboxymethyl) lysine protein adduct is a major immunological epitope in proteins modified with advanced glycation end products of the Maillard reaction. Biochemistry. 1996;35:8075-83.

31. Klebanoff SJ. Myeloperoxidase: friend and foe (Review). J Leukoc Biol. 2005;77:598-625.

32. Kutter $D$, Devaquet $P$, Vanderstocken G, Paulus JM, Marchal V, Gothot A. Consequences of total and subtotal myeloperoxidase deficiency: risk or benefit? Acta Haematol. 2000;1041:10-5.

33. Tang WH, Wu Y, Nicholls SJ, Hazen SL. Plasma myeloperoxidase predicts incident cardiovascular risks in stable patients undergoing medical management for coronary artery disease. Clin Chem. 2011;57:33-9.

34. Golubinskaya V, Brandt-Eliasson U, Gan LM, Kjerrulf M, Nilsson H. Endothelial function in a mouse model of myeloperoxidase deficiency. Biomed Res Int. 2014;2014:128046.

35. Jay D, Hitomi H, Griendling KK. Oxidative stress and diabetic cardiovascular complications. Free Radic Biol Med. 2006;40:183-92.

36. Nasr CE, Hoogwerf BJ, Faiman C, Reddy SS. United Kingdom Prospective Diabetes Study (UKPDS). Effects of glucose and blood pressure control on complications of type 2 diabetes mellitus. Cleve Clin J Med. 1999;66:247-53.

37. Zhang R, Brennan ML, Fu X, Aviles RJ, Pearce GL, Penn MS, et al. Association between myeloperoxidase levels and risk of coronary artery disease. JAMA. 2001;286:2136-42.

\section{Submit your next manuscript to BioMed Central and we will help you at every step:}

- We accept pre-submission inquiries

- Our selector tool helps you to find the most relevant journal

- We provide round the clock customer support

- Convenient online submission

- Thorough peer review

- Inclusion in PubMed and all major indexing services

- Maximum visibility for your research

Submit your manuscript at www.biomedcentral.com/submit

\section{() Biomed Central}

